\title{
Integration of the Visible Color Spectrum and the Rough Sets Theory in the Process of Expert Knowledge Extraction
}

\author{
Olga Pilipczuk \\ University of Szczecin \\ 71-101, Mickiewicza 64 \\ Szczecin, Poland
}

\begin{abstract}
This paper presents the basic problems encountered in the process of expert knowledge extraction. Several experiments were carried out to compare the effectiveness of using linguistic and color data during this process. Particular attention was given to the color spectrum sets, and an example of how they can be applied in the rough sets theory is provided. The main purpose of the paper is to prove that the color spectrum scale more closely reflects people's opinions than the linguistic scale does and that it is possible to effectively integrate the color spectrum scale with the rough sets theory to extract expert knowledge. The experiments were conducted on a group of real estate specialists to obtain knowledge rules during the process of buying a building plot. Opinions were collected by questionnaire and interview. The experiments confirmed the hypothesis.
\end{abstract}

\section{General Terms}

Rough Sets, Measurement Scale, Visible Color Spectrum, Knowledge Extraction, Color Coding.

\section{Keywords}

Rough Sets, Color Coding, Knowledge Extraction.

\section{INTRODUCTION}

Knowledge extraction is the process by which the knowledge engineer attempts to extract information from an expert: opinions on an object or a phenomenon, the evaluation of an object or a phenomenon, comments, notes, etc.

In the rough sets theory, an expert usually works with numerical or linguistic input data. A constraint of numerical data is that they are unable to reflect all of the information coming from the environment, whereas verbal information is not sufficiently precise and has a limited scale. For example, the expert will not be able to measure the "attractiveness" of a building plot using numbers. For a long time now, scientists have argued that phenomena or object descriptions based on linguistic data are very labor intensive, controversial, and imprecise. Typically, five to seven linguistic quantifiers are used; this significantly limits the precision of evaluating the object or criterion, and thus makes precise forecasting using verbal data impossible. In addition, for every man the same word can have different meanings. Scientists are still looking for new methods and tools for expert knowledge extraction that will allow the integration of the different data types: numerical, linguistic, image, and others.
A large number of articles on various aspects of rough sets and their applications have been published, with main papers contributed by Z. Pawlak, W. Pedrycz, R. Słowiński, A. Skowron, S. Tsumoto, Y. Yao, L.A. Zadeh, and many other scientists. Rough sets are applied in many domains, e.g., in medicine, economics, information technology, telecommunication, and marketing [1-13]. Several publications reveal the need to extend the traditional rough set approach and to integrate it with other methods and conceptions [5, 14-20]. Therefore, the idea of using color spectrum sets for expert knowledge extraction is introduced. A series of experiments were conducted to prove the hypothesis that information obtained by means of this scale type is more precise and that the knowledge (rules) obtained is more reliable.

Color and image data have become very popular in recent years. Scales of pain provide an example of how image data can be used in opinion acquisition. A pain scale measures a patient's pain intensity or other features and is based on selfreported philological data. Especially interesting are face pain scales, which were created, generally for children. The Pain Intensity Scales Pocket, a convenient pocket tool and a foldable set of intensity scales, can be bought on the Pain Resources Network web site. The scale includes a combination of progressive spectrum colors, verbal descriptions, expressive faces, and numeric ratings to indicate the degree of pain [21]. Color spectra have been already used in many studies to present different types of information. For example, such a scale is used in geographical research to represent the level of temperature, salinity, density, and frequency of the ocean biosphere [22]. In making medical diagnosis such a scale is used to indicate the surface plasmon resonance angle during the study of the live cell membrane [23] or in echocardiography images [24]. In physics, a spectrum scale is used, for example, to show the correlation between different spectral components during the investigation of a single electron transport through semiconductor nanostructure [25]. The color spectrum scale is also used in many other situations and fields of science.

Done in recent years, studies have shown that scales with the meaning of colors using spectrum analysis and accelerate the understanding of information conveyed [26, 27, 28, 29]. The scale of 21 colors was selected for further experiments (Fig. $1)$. 


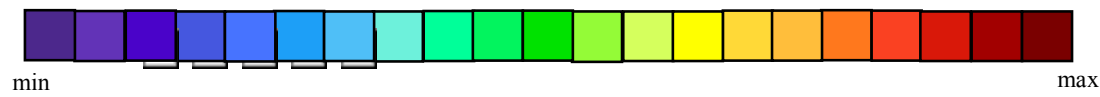

Figure 1. Spectrum scale with 21 colors

\section{EXPERIMENTS}

A human being can see and understand all colors in a spectrum in a natural intuitive way. The spectrum of colors is a part of the electromagnetic spectrum that can be detected by the human eye. The spectrum of colors consists of the following simple colors: violet, indigo, blue, cyan, green, yellow, orange and red. A simple color is a visual impression caused by an electromagnetic wave with a specified length between $380 \mathrm{~nm}$ and 740 nanometers.

Each color has a specific meaning. Cool colors are usually not reassuring. Violet is a combination of blue and red. Red brings dynamism and activity to distanced blue. Light blue often has an effect of calmness and relaxation. Green has the same calming effect as well as blue, but it also contains some of the energy of yellow. Generally, the green has the balancing and harmonizing impact. Warm colors convey emotions from simple optimism or hope to anger. These are typically energetic and positive colors. Yellow is the first warm color in the spectrum. It carries the warmth, joy, and at the same time it is gentle. The orange color usually creates excitement. Red has long been recognized as the color of strong emotions, and even aggression.

One of the ways of using color coding is by integrating them with the rough sets theory. To measure the effectiveness of such integration, two experiments were carried out. In the first experiment the possibility of creating reliable rules using the color spectrum scale was examined. The experiment was conducted on a group of real estate specialists to obtain knowledge rules during the process of buying a building plot. The opinions of 45 real estate experts on the attractiveness of the location, the quality of the land, and the price were analyzed. The opinions were extracted using the color spectrum scale as shown in Table 1.

At the beginning the transformation from color to numbers was done (Tab.2). All the collected data were represented as an information system, which is a pair $\mathrm{S}=(\mathrm{U}, \mathrm{A})$, where $\mathrm{U}$ and $\mathrm{A}$, are finite, nonempty sets called the universe, and the set of attributes such that a: $U \rightarrow$ Va for every a $\in A$. The information table assigns a value a (x) from $V_{a}$ to each attribute a and object $\mathrm{x}$ in the universe $\mathrm{U}[30,31]$. After that the data in the table were sorted.

The following condition attributes were defined: attractiveness of the location (c1), the quality of the land (c2), and price ware analyzed (c3).

The possible variants of decision were as follows:

1. I will buy this plot. - 4

2. I will look for something better; if I do not find something better, there is a high probability that I will buy it. - 3

3. I would rather not buy, but I will negotiate. - 2

4. I will definitely not buy it. - 1

Table 1. The process of data transformation

\begin{tabular}{|c|c|c|c|c|c|c|c|c|c|c|}
\hline answer & c1 & c2 & c3 & d & support & answer & c1 & c2 & c3 & d \\
\hline 1 & & & & 2 & 3 & 1 & 15 & 10 & 16 & 3 \\
\hline 2 & & & & 4 & 1 & 2 & 17 & 10 & 15 & 4 \\
\hline 3 & & & & 3 & 3 & 3 & 14 & 11 & 14 & 3 \\
\hline 4 & & & & 3 & 2 & 4 & 13 & 8 & 10 & 3 \\
\hline 5 & & & & 2 & 1 & 5 & 17 & 5 & 14 & 2 \\
\hline 6 & & & & 3 & 2 & 6 & 12 & 12 & 15 & 3 \\
\hline 7 & & & & 2 & 1 & 7 & 15 & 6 & 13 & 2 \\
\hline 8 & & & & 1 & 1 & 8 & 11 & 8 & 17 & 1 \\
\hline 9 & & & & 3 & 4 & 9 & 14 & 14 & 15 & 3 \\
\hline 10 & & & & 3 & 1 & 10 & 15 & 11 & 12 & 3 \\
\hline 11 & & & & 3 & 1 & 11 & 9 & 12 & 15 & 3 \\
\hline 12 & & & & 2 & 2 & 12 & 12 & 8 & 16 & 2 \\
\hline 13 & & & & 4 & 5 & 13 & 16 & 11 & 13 & 4 \\
\hline 14 & & & & 4 & 1 & 14 & 20 & 15 & 14 & 4 \\
\hline 15 & & & & 1 & 2 & 15 & 14 & 9 & 17 & 1 \\
\hline 16 & & & & 3 & 2 & 16 & 17 & 8 & 14 & 3 \\
\hline 17 & & & & 2 & 5 & 17 & 14 & 11 & 15 & 3 \\
\hline 18 & & & & 2 & 1 & 18 & 9 & 8 & 14 & 2 \\
\hline 19 & & & & 4 & 3 & 19 & 14 & 11 & 14 & 4 \\
\hline 20 & & & & 4 & 4 & 20 & 13 & 14 & 13 & 4 \\
\hline
\end{tabular}


The next step was the identification of lower and upper approximation. Thus, two operations should be defined, assigning to every $X \subseteq U$ two sets B: lower approximation $\underline{B}(X)$ and upper approximation $\bar{B}(X)[30]$ :

$$
\begin{aligned}
& \underline{B}(X)=\bigcup_{x \in U}\{B(x): B(x) \subseteq X\} \\
& \bar{B}(X)=\bigcup_{x \in U}\{B(x): B(x) \cap X \neq \varnothing\}
\end{aligned}
$$

In the next step the quality and the accuracy of the rough set were assessed. The accuracy of the rough-set representation of the set $\mathrm{X}$ is given by Pawlak [13] in the following formula:

$$
\alpha_{B}(X)=\frac{\operatorname{card}(\underline{B}(X))}{\operatorname{card}(\bar{B}(X))}
$$

The accuracy of the rough set representation of $\mathrm{X}, \alpha_{B}(X)$ is the ratio of the number of objects that can positively be placed in $\mathrm{X}$ to the number of objects that can possibly be placed in $\mathrm{X}$ - this provides a measure of how closely the rough set is approximating the target set.

Then, the dependency of attribute set $\mathrm{X}$ on attribute set $\mathrm{B}$ is given by formula, where $|U|$ denotes cardinality of $U$ [30]:

$$
\gamma=\frac{\sum_{i=1}^{N} \underline{B}\left(X_{i}\right)}{|U|}
$$

According to formulas (1), (2), (3) and (4), the following results were obtained:

$$
\begin{gathered}
\text { card } \underline{B}(X)=39 ; \text { card } \bar{B}(X)=51 \\
\gamma=0.87 ; \quad \alpha_{B}(X)=0.76
\end{gathered}
$$

Two disjoint classes of attributes were then distinguished in an information system, called condition and decision attributes. The system is called a decision table and denoted by $S=(U, C, D)$, where $C$ and $D$ are disjoint sets of condition and decision attributes, respectively. Every $X \subseteq U$ determines the sequence $c_{1}(x), \ldots, c_{n}(x)$; $d_{1}(x), \ldots, d_{m}(x)$, where $C=\left\{c_{1}, \ldots, c_{n}\right\} ; D=\left\{d_{1}, \ldots, d_{m}\right\}$.

Each rule consists of antecedent and consequent formulas, called premise and conclusion, respectively. Therefore, it can be seen as a consequence relation between premise and conclusion $C \rightarrow_{x} D$.

Currently the literature provides a rich set of measures introduced to highlight particularly important features of a single rule or of the rule set [32-34].

Support is one of the most popular measures of the rule attractiveness [30, 35]:

$$
\sup p_{x}(C, D)=|A(x)|=|C(x) \cap D(x)|
$$

Another measure used in classification is the strength of the decision rule $C \rightarrow_{x} D$, which depends on the support and cardinality of $\mathrm{U}$.

$$
\sigma_{x}(C, D)=\frac{\sup p_{x}(C, D)}{|U|}
$$

The next measure, the certainty factor of the decision rule, is defined as follows [30,35]:

$$
\operatorname{cer}_{x}(C, D)=\frac{|C(x) \cap D(X)|}{|C(x)|}=\frac{\sup p_{x}(C, D)}{|C(x)|}
$$

It is assumed that if the support of the rule is more than 1 and certainty is more than 0.5 , it means that this rule is "reliable". The reliability factor is defined by the following formula:

$$
\operatorname{rel}_{x}(C, D)=\sigma_{x}(C, D) \cdot \operatorname{cer}_{x}(C, D)
$$

The decision table below presents all the rule attractiveness measures for this experiment.

Table 3. The rule attractiveness measures for color scale and four decision variants

\begin{tabular}{ccccccccc}
\hline rule & $\mathbf{c}_{1}$ & $\mathbf{c}_{\mathbf{2}}$ & $\mathbf{c}_{\mathbf{3}}$ & $\mathbf{d}$ & supp & $\boldsymbol{\sigma}$ & cer & rel \\
\hline $\mathrm{R} 1$ & 9 & 8 & 14 & 2 & 1 & 0.02 & 1 & - \\
$\mathrm{R} 2$ & 9 & 12 & 15 & 3 & 1 & 0.02 & 1 & - \\
$\mathrm{R} 3$ & 11 & 8 & 17 & 1 & 1 & 0.02 & 1 & - \\
$\mathrm{R} 4$ & 12 & 8 & 16 & 2 & 2 & 0.04 & 1 & 0.04 \\
$\mathrm{R} 5$ & 12 & 12 & 15 & 3 & 2 & 0.04 & 1 & 0.04 \\
$\mathrm{R} 6$ & 13 & 8 & 10 & 3 & 2 & 0.04 & 1 & 0.04 \\
$\mathrm{R} 7$ & 13 & 14 & 13 & 4 & 4 & 0.08 & 1 & 0.08 \\
$\mathrm{R} 8$ & 14 & 9 & 17 & 1 & 2 & 0.04 & 1 & 0.04 \\
$\mathrm{R} 9$ & 14 & 11 & 14 & 3 & 3 & 0.06 & 0.5 & - \\
$\mathrm{R} 10$ & 14 & 11 & 14 & 4 & 3 & 0.06 & 0.5 & - \\
$\mathrm{R} 11$ & 14 & 11 & 15 & 2 & 5 & 0.11 & 1 & 0.11 \\
$\mathrm{R} 12$ & 14 & 14 & 15 & 3 & 4 & 0.08 & 1 & 0.08 \\
$\mathrm{R} 13$ & 15 & 6 & 13 & 2 & 1 & 0.02 & 1 & - \\
$\mathrm{R} 14$ & 15 & 10 & 16 & 2 & 3 & 0.06 & 1 & 0.06 \\
$\mathrm{R} 15$ & 15 & 11 & 12 & 3 & 1 & 0.02 & 1 & - \\
$\mathrm{R} 16$ & 16 & 11 & 13 & 4 & 5 & 0.11 & 1 & 0.11 \\
$\mathrm{R} 17$ & 17 & 5 & 14 & 2 & 1 & 0.02 & 1 & - \\
$\mathrm{R} 18$ & 17 & 8 & 14 & 3 & 2 & 0.04 & 1 & 0.04 \\
$\mathrm{R} 19$ & 17 & 10 & 15 & 4 & 1 & 0.02 & 1 & - \\
$\mathrm{R} 20$ & 20 & 15 & 14 & 4 & 1 & 0.02 & 1 & - \\
REL & & & & & & & & $\mathbf{0 . 6 4}$ \\
\hline & & & & & & & &
\end{tabular}

The sum of all reliability values for the current decision table determines the whole reliability of extracted rules.

$$
R E L=\sum_{x=1}^{n} r e l_{x}(C, D), \quad 0<\mathrm{REL}<1
$$

The next part of the experiment was divided into two stages. First, each criterion was described with the use of seven words, and attractiveness measures were calculated. Then, the same manipulations were made using five words to describe the criteria. In the second stage, the number of quantifications of the decision attribute was changed from four to two. Finally, the results of the first and the second stages were compared.

Experiment with the 5-word scale and four decision variants 
In this experiment the following condition attributes were used:

Location attractiveness:

Very attractive -5

Attractive - 4

Average attractiveness - 3

Unattractive - 2

Very unattractive -1

Land quality:

Very high - 5

High - 4

Average - 3

Low - 2

Very low- 1

Price:

Very high -5

High - 4

Average - 3

Low - 2

Very low -1

The decision variants were the same as in the second experiment.

Using formulas (3) and (4) the following results were obtained:

$$
\gamma=0.42 ; \quad \alpha_{B}(X)=0.26
$$

Table 4. The rule attractiveness measures for the 5-word scale and four decision variants

\begin{tabular}{|c|c|c|c|c|c|c|c|c|}
\hline rule & c1 & c2 & c3 & d & supp & $\boldsymbol{\sigma}$ & cer & rel \\
\hline R1 & 2 & 3 & 3 & 3 & 1 & 0.02 & 1 & - \\
\hline R2 & 3 & 2 & 2 & 3 & 2 & 0.04 & 1 & 0.04 \\
\hline R3 & 3 & 2 & 4 & 1 & 1 & 0.02 & 0.25 & - \\
\hline R4 & 3 & 2 & 4 & 2 & 3 & 0.067 & 0.75 & 0.05 \\
\hline R5 & 3 & 3 & 3 & 3 & 5 & 0.11 & 0.41 & - \\
\hline R6 & 3 & 3 & 3 & 4 & 7 & 0.15 & 0.58 & 0.087 \\
\hline R7 & 3 & 3 & 4 & 2 & 8 & 0.17 & 1 & 0.17 \\
\hline R8 & 4 & 2 & 3 & 2 & 2 & 0.04 & 0.5 & - \\
\hline R9 & 4 & 2 & 3 & 3 & 2 & 0.04 & 0.5 & - \\
\hline R10 & 4 & 2 & 4 & 1 & 2 & 0.04 & 1 & 0.04 \\
\hline R11 & 4 & 3 & 3 & 3 & 1 & 0.02 & 0.7 & - \\
\hline R12 & 4 & 3 & 3 & 4 & 5 & 0.11 & 0.83 & 0.09 \\
\hline R13 & 4 & 3 & 4 & 4 & 1 & 0.02 & 1 & - \\
\hline R14 & 4 & 4 & 4 & 3 & 4 & 0.088 & 1 & 0.088 \\
\hline R15 & 5 & 4 & 3 & 4 & 1 & 0.02 & 1 & - \\
\hline REL & & & & & & & & $\mathbf{0 . 5 6 5}$ \\
\hline
\end{tabular}

Experiment with the 7-word scale and four decision variants

In this experiment the following condition attributes were used:

Location attractiveness:

Absolutely attractive - 7
Very attractive -6

Attractive - 5

Average attractiveness - 4

Unattractive - 3

Very unattractive -2

Absolutely unattractive -1

Land quality:

Too high - 7

Very high -6

High - 5

Average - 4

Low - 3

Very low -2

Extremely low - 1

Price:

Too high - 7

Very high -6

High - 5

Average - 4

Low - 3

Very low -2

Extremely low - 1

According to formulas (3) and (4) the following results were obtained:

$$
\gamma=0.4 ; \quad \alpha_{B}(X)=0.25
$$

Table 5. The rule attractiveness measures for the 7-word scale and four decision variants

\begin{tabular}{|c|c|c|c|c|c|c|c|c|}
\hline rule & c1 & c2 & c3 & d & supp & $\boldsymbol{\sigma}$ & cer & rel \\
\hline R1 & 3 & 3 & 4 & 1 & 1 & 0.02 & 1 & - \\
\hline R2 & 3 & 4 & 5 & 1 & 1 & 0.02 & 1 & - \\
\hline R3 & 4 & 3 & 3 & 2 & 2 & 0.04 & 1 & - \\
\hline R4 & 4 & 3 & 5 & 1 & 1 & 0.02 & 1 & - \\
\hline R5 & 4 & 3 & 6 & 1 & 2 & 0.04 & 1 & 0.04 \\
\hline R6 & 4 & 4 & 4 & 1 & 3 & 0.067 & 0.3 & - \\
\hline R7 & 4 & 4 & 4 & 2 & 7 & 0.15 & 0.7 & 0.08 \\
\hline R8 & 4 & 4 & 5 & 1 & 6 & 0.13 & 0.54 & 0.07 \\
\hline R9 & 4 & 4 & 5 & 2 & 5 & 0.11 & 0.46 & - \\
\hline R10 & 5 & 2 & 4 & 1 & 1 & 0.02 & 1 & - \\
\hline R11 & 5 & 3 & 6 & 1 & 2 & 0.04 & 1 & 0.04 \\
\hline R12 & 5 & 4 & 4 & 2 & 6 & 0.13 & 1 & 0.13 \\
\hline R13 & 5 & 4 & 5 & 1 & 3 & 0.067 & 1 & 0.067 \\
\hline R14 & 6 & 2 & 4 & 1 & 1 & 0.02 & 1 & - \\
\hline R15 & 6 & 2 & 5 & 1 & 2 & 0.04 & 1 & 0.04 \\
\hline R16 & 6 & 3 & 5 & 2 & 1 & 0.02 & 1 & - \\
\hline R17 & 7 & 5 & 4 & 2 & 1 & 0.02 & 1 & - \\
\hline REL & & & & & & & & $\mathbf{0 . 4 6 7}$ \\
\hline
\end{tabular}

Experiment with the 21-color scale and two decision variants

In this experiment the decision variants were changed. The expert should give one of the following answers: "Yes, I will buy this building plot" or "No, I will not buy this building plot". 
According to formulas (3) and (4) the following results were obtained:

$$
\gamma=0.87 ; \quad \alpha_{B}(X)=0.76
$$

Table 6. The rule attractiveness measures for color scale and two decision variants

\begin{tabular}{|c|c|c|c|c|c|c|c|c|}
\hline rule & c1 & $\mathbf{c 2}$ & $\mathbf{c 3}$ & $\mathbf{d}$ & supp & $\boldsymbol{\sigma}$ & cer & rel \\
\hline R1 & 9 & 8 & 14 & 1 & 1 & 0.02 & 1 & - \\
\hline R2 & 9 & 12 & 15 & 2 & 1 & 0.02 & 1 & - \\
\hline R3 & 11 & 8 & 17 & 1 & 1 & 0.02 & 1 & - \\
\hline R4 & 12 & 8 & 16 & 1 & 2 & 0.04 & 1 & 0.04 \\
\hline R5 & 12 & 12 & 15 & 2 & 2 & 0.04 & 1 & 0.04 \\
\hline R6 & 13 & 8 & 10 & 1 & 2 & 0.04 & 1 & 0.04 \\
\hline R7 & 13 & 14 & 13 & 2 & 4 & 0.08 & 1 & 0.08 \\
\hline R8 & 14 & 9 & 17 & 1 & 2 & 0.04 & 1 & 0.04 \\
\hline R9 & 14 & 11 & 14 & 1 & 2 & 0.02 & 0.33 & - \\
\hline R10 & 14 & 11 & 14 & 2 & 4 & 0.08 & 0.66 & 0.058 \\
\hline R11 & 14 & 11 & 15 & 1 & 5 & 0.11 & 1 & 0.11 \\
\hline R12 & 14 & 14 & 15 & 2 & 4 & 0.08 & 1 & 0.08 \\
\hline R13 & 15 & 6 & 13 & 1 & 1 & 0.02 & 1 & - \\
\hline R14 & 15 & 10 & 16 & 2 & 3 & 0.06 & 1 & 0.06 \\
\hline R15 & 15 & 11 & 12 & 2 & 1 & 0.02 & 1 & - \\
\hline R16 & 16 & 11 & 13 & 2 & 5 & 0.11 & 1 & 0.11 \\
\hline R17 & 17 & 5 & 14 & 1 & 1 & 0.02 & 1 & - \\
\hline R18 & 17 & 8 & 14 & 2 & 2 & 0.04 & 1 & 0.04 \\
\hline R19 & 17 & 10 & 15 & 2 & 1 & 0.02 & 1 & - \\
\hline R20 & 20 & 15 & 14 & 2 & 1 & 0.02 & 1 & - \\
\hline REL & & & & & & & & $\mathbf{0 . 6 9 8}$ \\
\hline & & & & & & & \\
\hline
\end{tabular}

Experiment with the 5-word scale and two decision variants

According to formulas (3) and (4) the following results were obtained:

$$
\gamma=0.51 ; \quad \alpha_{B}(X)=0.34
$$

Table 7. The rule attractiveness measures for the 5-word scale and two decision variants

\begin{tabular}{|c|c|c|c|c|c|c|c|c|}
\hline rule & c1 & c2 & c3 & d & supp & $\boldsymbol{\sigma}$ & cer & rel \\
\hline R1 & 2 & 3 & 3 & 1 & 1 & 0.02 & 1 & - \\
\hline R2 & 3 & 2 & 2 & 1 & 1 & 0.02 & 1 & - \\
\hline R3 & 3 & 2 & 2 & 2 & 1 & 0.02 & 1 & - \\
\hline R4 & 3 & 2 & 4 & 1 & 4 & 0.08 & 1 & 0.089 \\
\hline R5 & 3 & 3 & 3 & 1 & 6 & 0.04 & 0.5 & - \\
\hline R6 & 3 & 3 & 3 & 2 & 6 & 0.22 & 0.5 & - \\
\hline R7 & 3 & 3 & 4 & 1 & 8 & 0.17 & 1 & 0.17 \\
\hline R8 & 4 & 2 & 3 & 1 & 2 & 0.04 & 0.5 & - \\
\hline R9 & 4 & 2 & 3 & 2 & 2 & 0.04 & 0.5 & - \\
\hline R10 & 4 & 2 & 4 & 1 & 2 & 0.04 & 1 & 0.04 \\
\hline R11 & 4 & 3 & 3 & 1 & 1 & 0.02 & 0.16 & \\
\hline R12 & 4 & 3 & 3 & 2 & 5 & 0.1 & 0.83 & 0.083 \\
\hline R13 & 4 & 3 & 4 & 1 & 1 & 0.02 & 1 & - \\
\hline R14 & 4 & 4 & 4 & 2 & 4 & 0.08 & 1 & 0.089 \\
\hline R15 & 5 & 4 & 3 & 2 & 1 & 0.02 & 1 & - \\
\hline REL & & & & & & & & $\mathbf{0 . 4 7 1}$ \\
\hline
\end{tabular}

Experiment with the 7-word scale and two decision variants According to formulas (3) and (4) the following results were obtained:

$$
\gamma=0.53 ; \quad \alpha_{B}(X)=0.36
$$

Table 8. The rule attractiveness measures for the 7-word scale and two decision variants

\begin{tabular}{|c|c|c|c|c|c|c|c|c|}
\hline Rule & C1 & $\mathbf{c 2}$ & $\mathbf{c 3}$ & $\mathbf{d}$ & $\mathbf{s u p p}$ & $\boldsymbol{\sigma}$ & cer & rel \\
\hline R1 & 3 & 3 & 4 & 1 & 1 & 0.02 & 1 & - \\
\hline R2 & 3 & 4 & 5 & 1 & 1 & 0.02 & 1 & - \\
\hline R3 & 4 & 3 & 3 & 2 & 2 & 0.04 & 1 & - \\
\hline R4 & 4 & 3 & 5 & 1 & 1 & 0.02 & 1 & - \\
\hline R5 & 4 & 3 & 6 & 1 & 2 & 0.04 & 1 & 0.04 \\
\hline R6 & 4 & 4 & 4 & 1 & 3 & 0.06 & 0.3 & - \\
\hline R7 & 4 & 4 & 4 & 2 & 7 & 0.15 & 0.7 & 0.08 \\
\hline R8 & 4 & 4 & 5 & 1 & 6 & 0.13 & 0.54 & 0.07 \\
\hline R9 & 4 & 4 & 5 & 2 & 5 & 0.11 & 0.46 & - \\
\hline R10 & 5 & 2 & 4 & 1 & 1 & 0.02 & 1 & - \\
\hline R11 & 5 & 3 & 6 & 1 & 2 & 0.04 & 1 & 0.04 \\
\hline R12 & 5 & 4 & 4 & 2 & 6 & 0.13 & 1 & 0.13 \\
\hline R13 & 5 & 4 & 5 & 1 & 3 & 0.06 & 1 & 0.06 \\
\hline R14 & 6 & 2 & 4 & 1 & 1 & 0.02 & 1 & - \\
\hline R15 & 6 & 2 & 5 & 1 & 2 & 0.04 & 1 & 0.04 \\
\hline R16 & 6 & 3 & 5 & 2 & 1 & 0.02 & 1 & - \\
\hline R17 & 7 & 5 & 4 & 2 & 1 & 0.02 & 1 & - \\
\hline REL & & & & & & & & 0.46 \\
\hline
\end{tabular}




\section{RESULTS AND DISCUSSION}

The results of the first experiment suggest that the dependency and accuracy of the obtained data are high enough since only three experts gave conflicting opinions. The whole reliability value is 0.7 . Thus, all of the facts help prove the hypothesis. Table 10 presents the results of the second experiment.

Table 9. The results of experiment

\begin{tabular}{|c|c|c|c|c|c|c|}
\hline \multirow{2}{*}{$\begin{array}{c}\text { Rule } \\
\text { measures }\end{array}$} & \multicolumn{3}{|c|}{ 4 decision variants } & \multicolumn{3}{c|}{ 2 decision variants } \\
\cline { 2 - 7 } & $\begin{array}{c}5 \\
\text { color }\end{array}$ & $\begin{array}{c}7 \\
\text { words }\end{array}$ & words & color & $\begin{array}{c}5 \\
\text { words }\end{array}$ & $\begin{array}{c}7 \\
\text { words }\end{array}$ \\
\hline dependency & 0.87 & 0.42 & 0.4 & 0.86 & 0.51 & 0.53 \\
\hline accuracy & 0.76 & 0.26 & 0.25 & 0.76 & 0.34 & 0.36 \\
\hline reliability & 0.64 & 0.56 & 0.46 & 0.69 & 0.47 & 0.46 \\
\hline
\end{tabular}

There is a large difference between both dependency and accuracy obtained by means of the color scale and the dependency and accuracy obtained by means of the linguistic scales. The worst results are observed when the 7-word scale and the 5-word scale are used in the situations with four decision variants.

The whole reliability values of the 5-word scale and the 7word scale obtained in the experiment with four decision variants do not differ too much and are about 0.47 and 0.46 , respectively; the whole reliability values from the experiment with two decision variants and 7 -words scale is the same.

The effects gained due to the introduction of the color coding into the process of knowledge extraction are, primarily, two to three times more precise. The experts know the industry very well thus their opinions were similar during the experiment, which shows that the quality of the data obtained depends mainly on expert competence, although sometimes even competent experts may have different opinions. The conducted experiments demonstrate that it is possible to create meaningful, as well as certain rules using the color spectrum sets.

\section{ACKNOWLEDGEMENTS}

The author wishes to thank the reviewers for their helpful comments.

\section{REFERENCES}

[1] Greco, S., Matarazzo, B., and Słowinski R. 1998. Rough approximation of a preference relation in a pair wise comparison table. In: Zopounidis S (Eds.) Operational Tools in the Management of Financial Risks. Kluwer Academic Publishers, Dordrecht, 121-136.

[2] Huang, X. and Zhang, Y. 2003. A new application of rough set to ECG recognition, In Proceedings of Int. Conf. on Machine Learning and Cybernetics. 3, 17291734.

[3] Hvidsten, T. and Komorowski, J. 2007. Rough Sets in Bioinformatics, In: J.F. Peters et al. (Eds.) Transactions on Rough Sets VII, Lecture Notes in Computer Science. $4400,225-243$.

[4] Mitra, P., Mitra, S., and Pal, S. 2001. Evolutionary modular MLP with rough sets and ID3 algorithm for staging of cervical cancer. Neural Computing and Applications. 10 (1), 67-76.

[5] Pedrycz, W. and Skowron, A. 2003. Rough sets, fuzzy sets in data mining, In: Handbook of Knowledge
Discovery \& Data Minining, W. Zytkow, W. Klosgen, (Eds.). Oxford University Press.

[6] Słowiński, R., and Zopounidis, C. 1994. Rough set sorting of rms according to bankruptcy risk, In: M. Paruccini (Eds.) Applying multiple criteria aid for decision to environmental management. Kluwer Academic Publishers, Dordrecht, 339-357.

[7] Słowiński, R. 1995. Rough set approach to decision analysis, AI Expert, 10, 18-25.

[8] Słowiński, R., Rough set theory and its applications to decision aid, Belgian Journal of Operation Research, 35 (3-4), 81-90.

[9] Stokic, E., Brtka, V., and Srdic, B. 2010. The synthesis of the rough set model for the better applicability of sagittal abdominal diameter in identifying high risk patients. Computers in Biology and Medicine. 40, 786790.

[10] Swiniarski, R. and Berzins, A. 1996. Rough Sets for Intelligent Data Mining, Knowledge discovering and Designing of an Expert Systems for on-line Prediction of Volleyball Game Progress. In: S. Tsumoto, S. Kobayashi, T. Yokomori, H. Tanaka, et al. (Eds.) Proc. of the Fourth International Workshop on Rough Sets. Fuzzy Sets and Machine Discovery, 6-8, 413-418.

[11] Swiniarski, R. 1998. Texture recognition based on rough sets 2D FFT feature extraction. In Proceedings of World Automation Congress, Anchorage, Alaska.

[12] Tsumoto, S and Tanaka, H. 1996. Extraction of medical diagnostic knowledge based on rough set based model selection rule induction. Fuzzy Sets and Machine Discovery, 426-436.

[13] Tsumoto, S. 2004. Mining diagnostic rules from clinical databases using rough sets and medical diagnostic model. Information Sciences: an International Journal, 162(2), 65-80.

[14] Hassanien, A., Abraham, A., Peters, J., Member, S., Peters, J., and Schaefer, G. 2008. Overview of roughhybrid approaches in image processing. In Proceedings of IEEE Conference on Fuzzy Systems, Hong Kong, $2135-2142$

[15] Lin, T. and Cercone, N. 1997. Rough sets and data mining. Kluwer, Dordrecht.

[16] Lin, T. and Liu, Q. 1994. Rough approximate operators: axiomatic rough set theory, In: Rough Sets, Fuzzy Sets and Knowledge Discovery, W. Ziarko (Eds.) SpringerVerlag, London, 256-260.

[17] Mao, C., Liu, S., and Lin, J. 2004. Classification of multispectral images through a rough-fuzzy neural network. Optical Engineering. 43 (1),103-112.

[18] Petrosino, A. and Salvi, G. 2006. Rough fuzzy set based scale space transforms and their use in image analysis. International Journal of Approximate Reasoning. 41 (2), 212-228.

[19] Sarkar, M. 2002. Rough-fuzzy functions in classification. Fuzzy Sets and Systems, 132 (3), 353-369.

[20]Yao, Y. 1997. Combination of rough and fuzzy sets based on alpha-level sets, In: T. Lin, N. Cercone, Rough sets and data mining. Kluwer, Dordrecht, 301-321. 
[21] Pain intensity scales. Product description. http://yhst90616455459028.stores.yahoo.net/pain-intensity-scalespocketsized.html

[22] Zappa, C., Ho, D., McGillis, W., Banner, M., Dacey, J., et al. 2009. Rain-induced turbulence and air-sea gas transfer, Journal of geophysical research, 114

[23] He, R., Chang, G., Wu H., Lin, C., Chiu, K., Su, Y., and Chen, S. 2006. Enhanced live cell membrane imaging using surface plasmon-enhanced total internal reflection fluorescence microscopy. Optical Express. 14 (20), 93079316.

[24] Yoshifuku, S., Chen, Sh., McMahon E., et al. 2007, Parametric detection and measurement of perfusion defects in attenuated contrast echocardiographic images. Journal of ultrasound in medicine. 26 (6) 7, 39-48.

[25] Ubbelohde, N., Fricke, Ch., Flindt, Ch, et al. 2012. Measurement of finite-frequency current statistics in a single-electron transistor. Nature Communications. 3, 612.

[26] Breslow, L. A, Ratwani, R. M, and Trafton J. G. 2009. Cognitive models of the influence of color scale on data visualization tasks. Human Factors. Jun. 51(3), 321-38.

[27] Folker, S., Sichelschmidt, L. and Ritter, H. 2005. Processing and Integrating Multimodal Material - The Influence of Color-Coding. In: B. G. Bara and L. Barsalou and M. Bucciarelli (Eds.), Proceedings of the 27th Annual Conference of the Cognitive Science Society, 690-695.
[28] Hyun, Y. 2008. Nonlinear Color Scales for Interactive Exploration. youngh/colorscales/nonlinear.html.

[29] Schulze-Wollgast P., Tominski, Ch., Schumann, H. 2005. Enhancing Visual Exploration by Appropriate Color Coding. In WSCG (Full Papers), 203-210.

[30] Pawlak, Z. and Słowiński, R. 1994. Decision analysis using rough sets. International Transactions in Operational Research. 1 (1), 107-114.

[31] Polkowski, L. 2003. Rough Sets. Mathematical Foundations. Physica-Verlag Heidelberg.

[32] Azevedo, P. and Jorge, A. M. 2007. Comparing rule Measures for Predictive Association Rules. In Proceedings of ECML. Springer-Verlag. Berlin Heidelberg, 510-517.

[33] Lenca, Ph., Meyer, P., Vaillant, B., and Lallich, S. 2008. On selecting interestingness measures for association rules: User oriented description and multiple criteria decision aid, European Journal of Operational Research. 184 (2), 610-626.

[34] Yao Y. and Zhong, N. 1999. An analysis of quantitative measures associated with rules. Lecture Notes in Artificial Intelligence, Springer-Verlag, Berlin, 479-488.

[35] Słowiński, R. and Greco, S. 2005. Measuring attractiveness of rules from the viewpoint of knowledge representation. Lecture Notes in Computer Science. $3528,950-953$. 